\title{
Indicação de cultivares de feijoeiro-comum baseada na avaliação conjunta de diferentes épocas de semeadura
}

\author{
Helton Santos Pereira(1), Leonardo Cunha Melo(1), Luís Cláudio de Faria(1), \\ Maria José Del Peloso(1), José Luís Cabrera Díaz ${ }^{(1)}$ e Adriane Wendland ${ }^{(1)}$
}

\begin{abstract}
(1)Embrapa Arroz e Feijão, Rodovia GO-462, Km 12, Caixa Postal 179, CEP 75375-000 Santo Antônio de Goiás, GO. E-mail: helton@cnpaf.embrapa.br, leonardo@cnpaf.embrapa.br, Icfaria@cnpaf.embrapa.br, mjpeloso@cnpaf.embrapa.br, cabrera@cnpaf.embrapa.br, adrianew@cnpaf.embrapa.br
\end{abstract}

Resumo - Os objetivos deste trabalho foram verificar a existência de interação entre genótipos de feijoeiro-comum e épocas de semeadura, avaliar a importância da interação complexa e verificar a necessidade de indicação de cultivares para cada época, em região de altitude intermediária nos estados do Paraná e Santa Catarina. Utilizaram-se avaliações de produtividade de grãos de 16 genótipos, em 12 ensaios realizados em duas épocas de semeadura. As análises de variância foram realizadas com decomposição da interação genótipos $\mathrm{x}$ ambientes. A percentagem complexa da interação para os pares de ambientes e também a correlação de Spearman entre épocas foram estimadas por meio de médias de produtividade e parâmetros de estabilidade dos genótipos, obtidos pela metodologia Annicchiarico. Detectaram-se diferenças entre épocas e presença de interação genótipos x épocas, mas com menor importância que as outras interações duplas com genótipos. As correlações de Spearman entre épocas mostraram interação predominantemente simples entre genótipos e épocas. A média da percentagem complexa da interação entre pares de ensaios mostrou que a alteração de classificação dos genótipos dentro de cada época tem a mesma magnitude do que a alteração entre épocas. Não é necessário indicar cultivares de feijoeiro comum para cada época isoladamente na região de estudo.

Termos para indexação: Phaseolus vulgaris, interação complexa, interação genótipo x ambiente.

\section{Indication of common bean cultivars based in joint evaluation of different growing seasons}

\begin{abstract}
The objectives of this work were to verify the genotype $\mathrm{x}$ growing seasons interaction in common beans, to evaluate the importance of the complex interaction and to verify the need to indicate cultivars for each growing season, in a region of intermediate altitude of Paraná and Santa Catarina states, Brazil. Grain yield data of 16 genotypes in 12 trials carried out in two growing seasons were used. Variance analysis was performed with the decomposition of genotype $\mathrm{x}$ environments interaction. The percentage of complex interaction was estimated between pairs of environments and also by the Spearman correlations between the growing seasons, using genotype's grain yield means and stability parameters obtained from Annicchiarico's methodology. Differences among growing seasons and genotype $\mathrm{x}$ growing season's interaction were detected; however, with lower importance than others double interactions with genotypes. The Spearman correlations between growing seasons showed that genotype $\mathrm{x}$ growing season's interaction is predominantly simple. The complex percentage mean of genotypes $\mathrm{x}$ growing season's interaction between pairs of environments showed that the alteration of classification is the same between pairs of a same growing season or between pairs of different growing seasons. It is not necessary to indicate common beans cultivars to each growing season, in the studied region.
\end{abstract}

Index terms: Phaseolus vulgaris, complex interaction, genotype $\mathrm{x}$ environments interaction.

\section{Introdução}

O feijoeiro-comum é uma cultura de grande importância no Brasil, com cultivo em grande parte do território nacional, nas mais variadas condições ambientais, sejam elas climáticas ou tecnológicas. Dessa forma, a interação genótipos $\mathrm{x}$ ambientes assume grande importância (Carbonell et al., 2004;
Oliveira et al., 2005; Melo et al., 2007; Pereira et al., 2009). Essa interação pode ser dividida em duas partes: simples, que não gera alteração na classificação dos genótipos; e complexa, que gera alteração (Cruz et al., 2004). Quando a parte predominante da interação é a complexa, deve-se aumentar o número de ambientes avaliados ou realizar a estratificação ambiental. 
Entre os fatores que afetam a interação genótipos $\mathrm{x}$ ambientes nas condições de cultivo do feijoeiro-comum, merecem destaque a variação entre anos, entre locais e entre épocas de semeadura. Na maior parte do Brasil, as épocas de semeadura podem ser divididas em três: a das águas, com semeadura de setembro a novembro, sem irrigação; a da seca, com semeadura de janeiro a março, também sem irrigação; e a de inverno, com semeadura de abril a julho, com presença de irrigação e, geralmente, com temperaturas mais baixas.

Ramalho et al. (1998) verificaram, em Minas Gerais, que as interações mais expressivas foram genótipos $\mathrm{x}$ épocas de semeadura (GxE) e genótipos x anos (GxA), em detrimento da interação genótipos x locais $(\mathrm{GxL})$, o que mostra que a avaliação dos genótipos em vários anos e nas diferentes épocas é mais importante do que a avaliação em vários locais. No entanto, Matos et al. (2007) afirmam que a interação GxL é muito importante nesse estado.

Os estados do Paraná e Santa Catarina são responsáveis por aproximadamente $35 \%$ da produção brasileira de feijão (Feijão, 2010) e, portanto, têm importância estratégica na avaliação das linhagens. A produção desses estados está distribuída em duas épocas tradicionais de semeadura, a das águas, também chamada de safra, com semeadura de setembro a novembro, e a da seca ou safrinha, com semeadura de janeiro a fevereiro.

A indicação de cultivares de feijoeiro-comum obedece às normas do Registro Nacional de Cultivares do Ministério da Agricultura, que exigem a indicação das cultivares por Estado e para cada época de semeadura. Assim, em cada estado deve-se obter um número mínimo de ensaios (três por ano, durante dois anos) para cada uma das épocas de semeadura (Brasil, 2006). Como o feijoeiro-comum é cultivado em 25 dos 26 estados brasileiros, e vários deles apresentam mais de uma época de semeadura, a indicação de cultivares para todos os estados produtores têm sido dificultada e, como consequência, não existem novas cultivares registradas para vários estados. Uma maneira de atenuar esse problema seria a indicação de cultivares de forma conjunta para as diferentes épocas de semeadura.

Atualmente, a avaliação dos genótipos é realizada separadamente nas diferentes épocas de semeadura, o que permite comparar o desempenho dos genótipos nessas épocas e verificar a existência de padrões de similaridade entre as épocas de semeadura, quanto à classificação dos genótipos. Dessa forma, podem-se obter informações úteis para subsidiar tecnicamente a indicação conjunta de cultivares para as diferentes épocas, o que reduziria o número de ensaios a serem realizados e, consequentemente, facilitaria a indicação de novas cultivares.

Os objetivos deste trabalho foram verificar a existência de interação entre os genótipos e as épocas de semeadura, avaliar a importância da interação complexa com relação ao ranqueamento dos genótipos avaliados, e verificar a necessidade de indicação de cultivares para cada época de semeadura isoladamente, em região de altitude intermediária nos estados do Paraná e Santa Catarina.

\section{Material e Métodos}

Os ensaios foram conduzidos nos anos de 2003 e 2004, em 12 ambientes nos estados do Paraná e de Santa Catarina, nos municípios de Ponta Grossa, PR $\left(25^{\circ} 05^{\prime} \mathrm{S}, 50^{\circ} 09^{\prime} \mathrm{W}, 969 \mathrm{~m}\right)$, Roncador, PR (24엉' $\left.52^{\circ} 16^{\prime} \mathrm{W}, 762 \mathrm{~m}\right)$, Abelardo Luz, SC $\left(26^{\circ} 33^{\prime} \mathrm{S}, 52^{\circ} 19^{\prime} \mathrm{W}\right.$, $760 \mathrm{~m})$, e Major Vieira, SC $\left(26^{\circ} 22^{\prime} \mathrm{S}, 50^{\circ} 19^{\prime} \mathrm{W}\right.$, $786 \mathrm{~m}$ ), todos de altitude intermediária (760 a $970 \mathrm{~m}$ ), nas épocas de semeadura das águas, setembro a novembro, e da seca, janeiro a março. Foram coletados dados de temperatura máxima e mínima e de precipitação, durante a execução dos ensaios (Tabela 1).

O delineamento experimental utilizado foi o de blocos ao acaso, com três repetições e parcelas de quatro linhas, com quatro metros de comprimento. Os dados de produtividade foram coletados nas duas linhas centrais. Cada ensaio foi constituído por 16 genótipos do grupo comercial carioca: CNFC's 9458, 9471, 9484, 9494, 9500, 9504, 9506, 9518, CNFE 8009, Carioca 11, BRS 9435 Cometa, BRS Estilo, Pérola, Iapar 81, Carioca Pitoco e FTS Magnífico.

Os dados de produtividade foram submetidos à análise de variância individual, considerando-se o efeito de tratamentos e locais como fixos. Para realização das análises, foram utilizados os aplicativos Genes (Cruz, 2007) e Sisvar (Ferreira, 2008). Em seguida, foram realizadas análises conjuntas para cada época de semeadura, para obtenção das médias de produtividade dos genótipos. Também foi realizada análise conjunta das duas épocas utilizadas, para decomposição da interação genótipos $\mathrm{x}$ ambientes em genótipos x épocas de semeadura e genótipos x locais/anos. As médias 
foram comparadas utilizando-se o teste de agrupamento de Scott \& Knott (1974), a 10\% de probabilidade. Esse nível de significância foi utilizado para diminuir a probabilidade de ausência de discriminação entre genótipos devido ao erro tipo II. Segundo Zimmerman (2004), esse procedimento é recomendável quando são esperadas pequenas diferenças entre os tratamentos.

Esses 12 ensaios foram utilizados, para que os locais fossem constantes nas duas épocas de semeadura, em cada ano. Dessa forma, os locais de avaliação foram Roncador, Ponta Grossa e Abelardo Luz, nas duas épocas de 2003, e Major Vieira, Ponta Grossa e Abelardo Luz, nas duas épocas de 2004. Utilizando-se esse grupo de ensaios, denominado de desbalanceado, o efeito de épocas foi isolado do efeito de anos e locais na decomposição da interação genótipos x ambientes. A utilização desse grupo de ensaios, nos mesmos locais, nas duas épocas de semeadura, possibilita uniformizar alguns fatores relacionados à condução dos ensaios que certamente seriam variáveis se fossem utilizados locais não constantes nas épocas, o que interferiria no resultado.

Para identificação da importância de cada fonte de variação da análise conjunta, foi estimada a contribuição de cada uma delas na variação total, tendo-se utilizado a estimativa do coeficiente de determinação $\left(\mathrm{R}^{2}\right)$, em conformidade com Ramalho et al. (1998), por meio da expressão: $\mathrm{R}_{\mathrm{i}}{ }^{2}=\mathrm{SQ}_{\mathrm{i}} / \mathrm{SQ}_{\mathrm{t}}$, em que: $\mathrm{SQ}_{\mathrm{i}}$ é a soma de quadrados da fonte de variação $\mathrm{i}, \mathrm{e} \mathrm{SQ}_{\mathrm{t}}$ é a soma de quadrados total.

Para verificação da importância da interação complexa, foram obtidas estimativas da percentagem complexa da interação, segundo Cruz \& Castoldi (1991), entre os pares de ambientes da época das águas, entre os pares de ambientes da época da seca e entre os pares de ambientes com épocas de semeadura distintas. Como alternativa para verificar a importância da interação complexa, foi obtida a estimativa de correlação de Spearman entre as duas épocas de semeadura, com base na média geral dos genótipos em cada época.

A análise de estabilidade e adaptabilidade dos genótipos, relativa a cada uma das épocas, foi realizada pela metodologia de Annicchiarico (1992), como outra forma de comparar as épocas de semeadura. Essa metodologia avalia a estabilidade por meio do risco associado em relação à adoção das cultivares, que é baseado no índice de confiança genotípico. Esse

Tabela 1. Temperatura máxima $\left(\mathrm{T}_{\max }\right)$, mínima $\left(\mathrm{T}_{\min }\right)$ e precipitação (Prec.) nos locais de avaliação de ensaios de feijoeiro comum $^{(1)}$.

\begin{tabular}{|c|c|c|c|c|c|c|c|c|c|c|c|c|c|c|c|}
\hline \multirow[t]{2}{*}{ Mês } & \multicolumn{3}{|c|}{ Ponta Grossa, PR } & \multicolumn{3}{|c|}{ Abelardo Luz, SC } & \multicolumn{3}{|c|}{ Roncador, PR } & \multicolumn{3}{|c|}{ Major Vieira, SC } & \multicolumn{3}{|c|}{ Geral } \\
\hline & $\mathrm{T}_{\max }$ & $\mathrm{T}_{\min }$ & Prec. & $\mathrm{T}_{\max }$ & $\mathrm{T}_{\min }$ & Prec. & $\mathrm{T}_{\max }$ & $\mathrm{T}_{\min }$ & Prec. & $\mathrm{T}_{\max }$ & $\mathrm{T}_{\min }$ & Prec. & $\mathrm{T}_{\max }$ & $\mathrm{T}_{\min }$ & Prec. \\
\hline & \multicolumn{15}{|c|}{ Seca, 2003} \\
\hline Fev. & 29,1 & 21,9 & 16,8 & 27,1 & 18,2 & 213,9 & 28,8 & 22,4 & 75,0 & - & - & - & - & - & - \\
\hline Mar. & 27,4 & 17,0 & 73,2 & 25,7 & 18,9 & 46,1 & 27,8 & 18,6 & 141,0 & - & - & - & - & - & - \\
\hline Abr. & 25,8 & 14,6 & 104,4 & 23,5 & 10,8 & 142,5 & 25,9 & 16,8 & 117,4 & - & - & - & - & - & - \\
\hline Maio & 21,7 & 8,7 & 30,4 & 19,7 & 7,3 & 49,8 & 22,5 & 12,2 & 47,6 & - & - & - & - & - & - \\
\hline \multirow[t]{2}{*}{ Média } & 25,9 & 15,6 & 56,2 & 24,0 & 13,8 & 113,1 & 26,3 & 17,5 & 95,3 & - & - & - & 25,4 & 15,6 & 88,2 \\
\hline & \multicolumn{15}{|c|}{ Águas, 2003} \\
\hline Out. & 25,7 & 14,1 & 101,6 & 24,6 & 12,5 & 169,9 & 27,2 & 15,8 & 133,0 & - & - & - & - & - & - \\
\hline Nov. & 26,3 & 14,7 & 161,0 & 24,7 & 13,1 & 276,8 & 27,4 & 16,5 & 126,2 & - & - & - & - & - & - \\
\hline Dez. & 27,3 & 16,7 & 143,4 & 25,0 & 14,2 & 477,7 & 27,3 & 17,5 & 229,8 & - & - & - & - & - & - \\
\hline Jan. & 26,7 & 17,0 & 102,6 & 26,0 & 15,2 & 80,0 & 28,2 & 18,3 & 83,4 & - & - & - & - & - & - \\
\hline \multirow[t]{2}{*}{ Média } & 26,5 & 15,6 & 127,2 & 25,1 & 13,8 & 251,1 & 27,6 & 17,0 & 143,1 & - & - & - & 26,4 & 15,5 & 173,8 \\
\hline & \multicolumn{15}{|c|}{ Seca, 2004} \\
\hline Fev. & 27,1 & 16,7 & 41,2 & 25,8 & 13,6 & 132,9 & - & - & - & 27,7 & 14,9 & 93,4 & - & - & - \\
\hline Mar. & 26,4 & 15,6 & 96,0 & 26,4 & 12,9 & 58,5 & - & - & - & 26,8 & 14,1 & 81,0 & - & - & - \\
\hline Abr. & 25,1 & 15,8 & 160,2 & 24,6 & 13,7 & 210,7 & - & - & - & 24,9 & 13,8 & 84,6 & - & - & - \\
\hline Maio & 18,9 & 11,0 & 198,0 & 17,1 & 7,8 & 164,4 & - & - & - & 19,8 & 9,2 & 107,7 & - & - & - \\
\hline Média & 24,4 & 14,8 & 123,9 & 23,5 & 12,0 & 141,6 & - & - & - & 24,8 & 13,0 & 91,7 & 24,2 & 13,3 & 119,9 \\
\hline & \multicolumn{15}{|c|}{ Águas, 2004} \\
\hline Out. & 24,2 & 13,0 & 239,6 & 24,3 & 11,3 & 212,0 & - & - & - & 25,5 & 12,1 & 285,1 & - & - & - \\
\hline Nov. & 25,5 & 15,1 & 171,2 & 23,9 & 12,7 & 217,6 & - & - & - & 26,6 & 14,0 & 90,0 & - & - & - \\
\hline Dez. & 26,2 & 16,1 & 156,8 & 25,1 & 13,8 & 109,7 & - & - & - & 26,5 & 14,7 & 88,2 & - & - & - \\
\hline Jan. & 26,1 & 17,8 & 253,8 & 27,0 & 15,8 & 285,7 & - & - & - & 26,0 & 16,1 & 47,1 & - & - & - \\
\hline Média & 25,2 & 15,5 & 205,4 & 25,1 & 13,4 & 206,3 & - & - & - & 26,2 & 14,2 & 128,0 & 25,5 & 14,4 & 179,9 \\
\hline
\end{tabular}


índice é estimado por: $\omega_{\mathrm{i}(\mathrm{g})}=\hat{\mu}_{\mathrm{i}(\mathrm{g})}-\mathrm{Z}_{(1-\alpha)} \hat{\sigma}_{\mathrm{zi}(\mathrm{g})}$, tendo-se considerado todos os ambientes, em que: $\hat{\mu}_{\mathrm{i}(\mathrm{g})}$ é a média percentual dos genótipos i; $\hat{\sigma}_{\mathrm{z}_{\mathrm{i}}(\mathrm{g})}$ é o desvio-padrão dos valores $z_{\mathrm{ij}}$, associado ao i-ésimo genótipo; $z_{(1-\alpha)}$ é o percentil da função de distribuição normal padrão. O coeficiente de confiança adotado foi de $75 \%$, isto é, $\alpha=0,25$.

Foi obtida a estimativa de correlação de Spearman entre os parâmetros de estabilidade e adaptabilidade dos genótipos em cada época, para que se pudesse comparar a classificação dos genótipos quanto a esses parâmetros, nas duas épocas.

Foram utilizados dados de 8 dos 12 ensaios realizados, para isolar todos os fatores (genótipos, locais, épocas e anos) e detalhar o efeito de cada um deles, o que possibilitou um total balanceamento entre os fatores estudados, para que fosse possível realizar análises conjuntas por épocas de semeadura (águas e seca) e também uma análise conjunta geral, com decomposição da interação. Esses oito ensaios foram os realizados nos municípios de Ponta Grossa e Abelardo Luz, nas duas épocas de semeadura e nos dois anos. Também foram obtidas as estimativas de $\mathrm{R}^{2}$ e da correlação de Spearman.

\section{Resultados e Discussão}

As médias de produtividade dos ensaios variaram de 985 a $3.946 \mathrm{~kg} \mathrm{ha}^{-1}$, e os valores de coeficiente de variação $(\mathrm{CV})$ variaram de 7 a 19\%, com indicação de boa precisão experimental (Tabela 2). Dos seis ensaios conduzidos na época das águas, cinco apresentaram produtividade superior a $3.000 \mathrm{~kg} \mathrm{ha}^{-1}$, e o ensaio de menor produtividade média também foi conduzido nessa época ( $\left.985 \mathrm{~kg} \mathrm{ha}^{-1}\right)$. Já na época da seca, dos seis ensaios conduzidos, apenas um obteve média acima de $3.000 \mathrm{~kg} \mathrm{ha}^{-1}$ e dois apresentaram média abaixo de $2.000 \mathrm{~kg} \mathrm{ha}^{-1}$. Na observação dos dados parcialmente balanceados, a média geral de produtividade para a época das águas foi de $2.977 \mathrm{~kg} \mathrm{ha}^{-1}$, estatisticamente superior à da seca, que foi de $2.177 \mathrm{~kg}^{-1}$ (Tabela 3).

Nos dados desbalanceados, a análise conjunta confirmou a presença de variabilidade entre os genótipos e a diferença entre as combinações de local/ano (Tabela 4). Também foi observada diferença entre as épocas de semeadura. Todas as interações foram significativas, inclusive genótipos $\mathrm{x}$ épocas $(\mathrm{GxE})$, o que indica que existe resposta diferente dos genótipos às épocas de semeadura. A interação pode ser predominantemente simples, sem causar alteração na classificação dos genótipos, ou complexa, que leva à alteração na classificação (Cruz et al., 2004).

$\mathrm{Na}$ análise das estimativas da percentagem complexa da interação genótipos $\mathrm{x}$ ambientes entre as médias dos genótipos nos pares de ambientes, a média dentro de cada época foi de 78\% (68\% na época das águas e $87 \%$ na seca), percentagem igual à média entre épocas diferentes (Tabela 5). A semelhança entre essas estimativas indica que a variação na classificação dos genótipos entre as épocas tem magnitude semelhante à variação dentro de uma mesma época e que a variação entre épocas tem pequena influência na classificação

Tabela 2. Resumo das análises de variância, para produtividade de grãos, dos 12 ensaios de feijoeiro comum tipo carioca.

\begin{tabular}{|c|c|c|c|c|c|}
\hline \multirow[t]{2}{*}{ Cidade } & \multicolumn{2}{|c|}{ Quadrados médios } & \multirow[t]{2}{*}{$\mathrm{p}^{(1)}$} & \multirow[t]{2}{*}{ Média geral $\left(\mathrm{kg} \mathrm{ha}^{-1}\right)$} & \multirow[t]{2}{*}{ CV $(\%)$} \\
\hline & Genótipos & Erro & & & \\
\hline & \multicolumn{5}{|c|}{ Seca, 2003} \\
\hline Ponta Grossa, PR & 629.799 & 144.728 & 0,000 & 2.182 & 17 \\
\hline Abelardo Luz, SC & 252.422 & 52.618 & 0,000 & 1.919 & 12 \\
\hline \multirow[t]{2}{*}{ Roncador, PR } & 401.996 & 44.317 & 0,000 & 1.423 & 15 \\
\hline & \multicolumn{5}{|c|}{ Águas, 2003} \\
\hline Ponta Grossa, PR & 416.380 & 100.214 & 0,000 & 3.688 & 9 \\
\hline Abelardo Luz, SC & 838.609 & 346.452 & 0,019 & 3.028 & 19 \\
\hline \multirow[t]{2}{*}{ Roncador, PR } & 124.046 & 35.767 & 0,002 & 985 & 19 \\
\hline & \multicolumn{5}{|c|}{ Seca, 2004} \\
\hline Ponta Grossa, PR & 449.786 & 82.048 & 0,000 & 3.141 & 9 \\
\hline Abelardo Luz, SC & 343.446 & 58.524 & 0,000 & 2.331 & 10 \\
\hline \multirow[t]{2}{*}{ Major Vieira, SC } & 297.010 & 57.126 & 0,000 & 2.067 & 12 \\
\hline & \multicolumn{5}{|c|}{ Águas, 2004} \\
\hline Ponta Grossa, PR & 1.210 .490 & 200.558 & 0,000 & 3.202 & 14 \\
\hline Abelardo Luz, SC & 419.058 & 80.233 & 0,000 & 3.946 & 7 \\
\hline Major Vieira, SC & 365.775 & 123.320 & 0,006 & 3.012 & 12 \\
\hline
\end{tabular}

(1)Probabilidade de existência de diferenças significativas entre genótipos. 


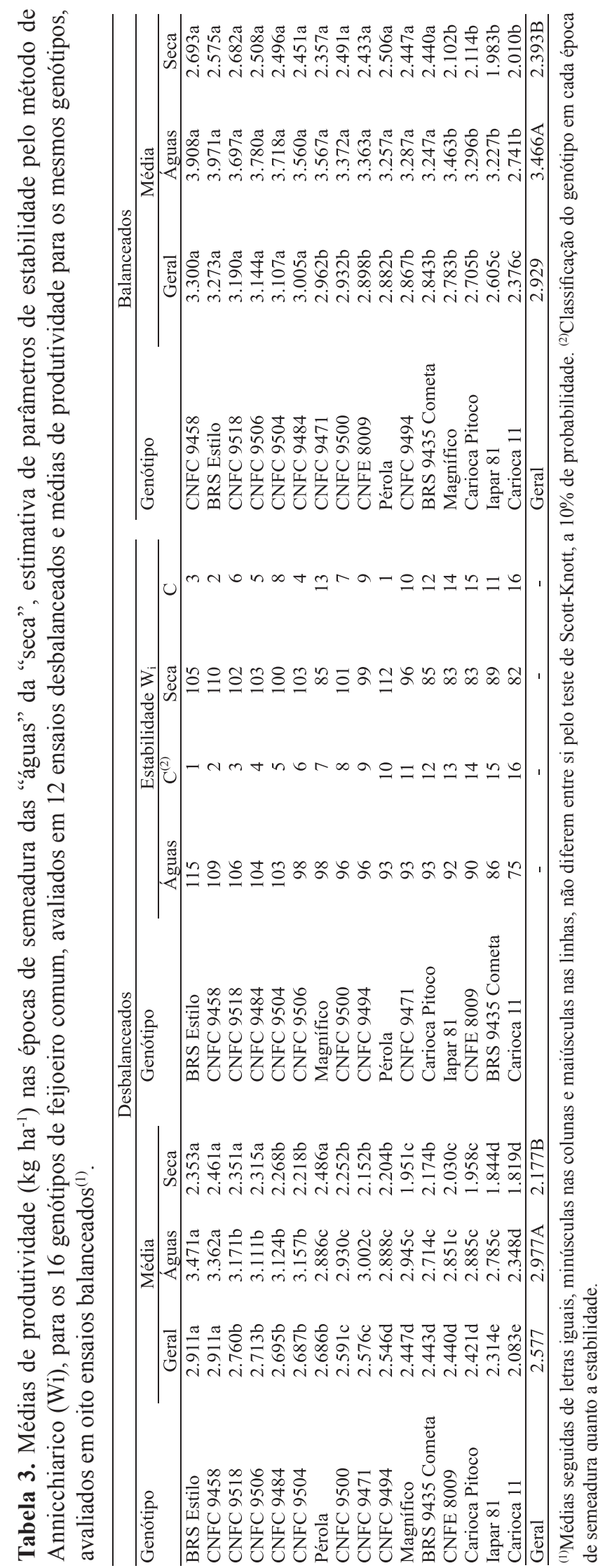

final dos genótipos, quando se considera avaliações em diferentes anos e locais.

Uma alternativa para verificar a predominância da parte complexa da interação é estimar a correlação de Spearman entre a média geral dos genótipos, em cada época. Essa estimativa foi alta $(0,69)$, o que indica que a interação do tipo simples é predominante e que a classificação dos genótipos deve ser pouco alterada (Cruz et al., 2004). Assim, as diferenças de classificação obtidas com os pares de ambientes são devidas a outros fatores, que não a época de semeadura.

A estimativa de correlação de Spearman entre os parâmetros de estabilidade e adaptabilidade dos genótipos nas duas épocas foi de 0,76 , o que mostra que os genótipos mais estáveis foram os mesmos, nas duas épocas de semeadura (Tabela 3). Apenas o genótipo Pérola apresentou grande variação quanto à classificação pela estabilidade e adaptabilidade.

Ao se avaliar os valores do coeficiente de determinação (Tabela 4), nota-se que o efeito de locais/ anos $(46 \%)$ foi cerca de três vezes maior do que o efeito de épocas (16\%), o que indica que existe maior variação entre os locais/anos do que entre as épocas de semeadura. É importante ressaltar que o efeito de anos confunde-se com o de locais. Entretanto, existem relatos de que o efeito de anos tem menor importância, em relação aos de épocas de semeadura e locais. Ramalho et al. (1998) constataram que os fatores locais, anos e épocas explicam 17\%,11\% e 19\%, respectivamente, ao avaliar as épocas de semeadura da seca e do inverno, contrastantes com relação à temperatura, incidência de doenças e disponibilidade de água, o que justificaria

Tabela 4. Resumo da análise de variância conjunta, para a produtividade de grãos, com decomposição da interação genótipos x ambientes, dos 12 ensaios de feijoeiro comum tipo carioca.

\begin{tabular}{lrccr}
\hline Fonte de variação & GL & Quadrado médio & $\mathrm{p}^{(1)}$ & $\mathrm{R}^{2}$ \\
\hline Genótipos (G) & 15 & 1.692 .168 & 0,000 & 4,5 \\
Local/ano (LA) & 5 & 51.705 .710 & 0,000 & 45,5 \\
Época (E) & 1 & 92.062 .425 & 0,000 & 16,2 \\
GxLA & 75 & 450.676 & 0,000 & 5,9 \\
GxE & 15 & 324.117 & 0,002 & 0,9 \\
LAxE & 5 & 16.118 .829 & 0,000 & 14,2 \\
GxLAxE & 75 & 295.830 & 0,000 & 3,9 \\
Resíduo & 384 & 132.812 & - & 8,9 \\
\hline Total & 575 & - & - \\
\hline Média (kg ha & -15 \\
\hline CV $(\%)$ & \multicolumn{5}{c}{ 2.576 } \\
(1)Probabilidade de existência de diferenças significativas entre genótipos.
\end{tabular}


a maior importância observada por esses autores na variação entre épocas.

A interação GxE foi responsável por apenas $0,9 \%$ da variação total, o menor valor por fonte de variação, o que indica sua pequena importância neste estudo. A interação mais importante relativa à fonte de variação genótipos foi a genótipo x locais/ano (GxLA), sete vezes maior que GxE, o que indica que a avaliação de genótipos em vários locais/anos é mais importante do que a avaliação nas duas épocas de semeadura (Tabela 3).

As médias dos genótipos em cada época de semeadura mostram que os de melhor desempenho foram os mesmos nas duas épocas. Na época das águas, os genótipos de melhor desempenho foram BRS Estilo e CNFC 9458, sem diferenças significativas pelo teste de médias com dados desbalanceados (Tabela 3). Já na época da seca, o primeiro grupo de médias foi formado pelos genótipos Pérola, CNFC 9458, BRS Estilo, CNFC 9518 e CNFC 9506. Considerando as duas épocas em conjunto, os genótipos de maior média foram BRS Estilo e CNFC 9458. Dessa forma, as diferenças entre as duas épocas de semeadura não afetaram a seleção dos genótipos superiores, já que, em ambas, eles foram os mesmos (BRS Estilo e CNFC 9458). Entretanto, alguns genótipos, como o Pérola, apresentaram desempenho contrastante nas duas épocas.

Como o conjunto de dados utilizado foi desbalanceado, também foram realizadas análises utilizando-se somente os oito ensaios em Abelardo Luz e Ponta Grossa, em todos os anos e safras. Esses ensaios permitiram uma análise completamente balanceada e a individualização e maior detalhamento da importância de cada fonte de variação para a variação total, com separação dos efeitos de anos e locais comdados balanceados. Essa análise mostrou diferenças significativas para todas as fontes de variação, com exceção das interações genótipos x locais x épocas, genótipos $\mathrm{x}$ locais $\mathrm{x}$ anos e genótipos $\mathrm{x}$ locais $\mathrm{x}$ épocas $\mathrm{x}$ anos (Tabela 6). As fontes de variação locais e anos representaram $2,0 \%$ e $6,8 \%$ da variação total, respectivamente, num total de $8,8 \%$, valor inferior aos 45,5\% obtidos na análise anterior (Tabela 4). A fonte de variação épocas explicou $39,5 \%$ da variação total, valor muito superior aos $16,2 \%$ obtidos anteriormente. A divergência entre os resultados devese, principalmente, à redução da variação total ocorrida na análise com dados balanceados, e não ao aumento na variação entre épocas.

As interações genótipos x locais $(\mathrm{GxL})$ e genótipos $x$ anos $(G x A)$ foram significativas $(p<0,01)$ e representaram 5,0 e 3,0\% da variação total. A interação de GxE foi significativa apenas a 5\% ( $\mathrm{p}=0,035)$, e explicou $1,5 \%$ da variação total (Tabela 6). Esses valores indicam que a interação $\mathrm{GxE}$ apresenta menor importância do que as interações GxL e GxA, que representaram 30 e $50 \%$ dos $\mathrm{R}^{2}$ obtidos para essas fontes de variação, respectivamente. Esse resultado está de acordo com o observado anteriormente

Tabela 5. Estimativas da porcentagem complexa da interação genótipos x ambientes entre os pares de ensaios de feijoeiro comum tipo carioca.

\begin{tabular}{|c|c|c|c|c|c|c|c|c|c|c|c|}
\hline Ensaios & 2 & 3 & 4 & 5 & 6 & 7 & 8 & 9 & 10 & 11 & 12 \\
\hline 1 Ponta Grossa, águas de 2003 & 60 & $60 *$ & 74 & 87 & $59 *$ & 60 & $55^{*}$ & 87 & 87 & $88 *$ & 99 \\
\hline 2 Abelardo Luz, águas de 2003 & & $53 *$ & 100 & 80 & $59 *$ & 95 & $80 *$ & 57 & 38 & $75^{*}$ & 97 \\
\hline 3 Roncador, águas de 2003 & & & $60 *$ & $61 *$ & $60 *$ & $59 *$ & $59 *$ & $90 *$ & $74 *$ & $78 *$ & $79 *$ \\
\hline 4 Ponta Grossa, águas de 2004 & & & & 54 & $64 *$ & 54 & $77 *$ & 70 & 100 & $83 *$ & 49 \\
\hline 5 Abelardo Luz, águas de 2004 & & & & & $81 *$ & 81 & $94 *$ & 76 & 100 & $99 *$ & 77 \\
\hline 6 Major Vieira, águas de 2004 & & & & & & $56^{*}$ & $68 *$ & $74 *$ & $85 *$ & $88 *$ & $99 *$ \\
\hline 7 Ponta Grossa, seca de 2003 & & & & & & & $56^{*}$ & 76 & 100 & $69 *$ & 77 \\
\hline 8 Abelardo Luz, seca de 2003 & & & & & & & & $100 *$ & $100^{*}$ & $86^{*}$ & $100 *$ \\
\hline 9 Roncador, seca de 2003 & & & & & & & & & 91 & $94 *$ & 83 \\
\hline 10 Ponta Grossa, seca de 2004 & & & & & & & & & & $81 *$ & 95 \\
\hline 11 Abelardo Luz, seca de 2004 & & & & & & & & & & & $80 *$ \\
\hline 12 Major Vieira, seca de 2004 & & & & & & & & & & & \\
\hline Porcentagem complexa da interação & $\mathrm{N}$ & \multicolumn{4}{|c|}{ Média (Parcialmente balanceado) } & \multicolumn{2}{|c|}{$\mathrm{N}$} & \multicolumn{4}{|c|}{ Média (Totalmente balanceado) } \\
\hline Dentro da época das águas & 15 & \multicolumn{4}{|c|}{68} & \multicolumn{2}{|c|}{6} & \multicolumn{4}{|c|}{76} \\
\hline Dentro da época da seca & 15 & \multicolumn{4}{|c|}{87} & \multicolumn{2}{|c|}{6} & \multicolumn{4}{|c|}{87} \\
\hline Dentro de épocas & 30 & \multicolumn{4}{|c|}{78} & \multicolumn{2}{|c|}{12} & \multicolumn{4}{|c|}{81} \\
\hline Entre as épocas & 36 & \multicolumn{4}{|c|}{78} & \multicolumn{2}{|c|}{16} & \multicolumn{4}{|c|}{77} \\
\hline
\end{tabular}

*Pares que somente estão no conjunto de dados parcialmente balanceados. $\mathrm{N}$, número de observações que deram origem à média. 
(Tabela 4). Ramalho et al. (1998), ao trabalhar com três locais nas épocas da seca e inverno, em Minas Gerais, encontraram estimativas de $\mathrm{R}^{2}$ de $1,9 \%$ para a interação GxE, 1,9\% para GxA e 1,6\% para $\mathrm{GxL}$ - esta última não significativa -, e concluíram que a avaliação em mais épocas e anos é mais importante do que a avaliação em mais locais.

No Paraná e em Santa Catarina, é esperada menor variação no comportamento dos genótipos entre as épocas, já que, nesses estados, existem duas épocas de semeadura, ambas sem irrigação e com menor variação climática, o que pode ser constatado nas médias de temperatura máxima, mínima e precipitação da época da seca $\left(24,8^{\circ} \mathrm{C}, 14,5^{\circ} \mathrm{C}\right.$ e $104 \mathrm{~mm}$, respectivamente) e da época das águas $\left(26,0^{\circ} \mathrm{C}, 15,0^{\circ} \mathrm{C}\right.$ e $\left.177 \mathrm{~mm}\right)$, obtidas nos anos de 2003 e 2004, nos locais de avaliação (Tabela 1).

Nos dados balanceados, a estimativa média da percentagem complexa da interação genótipos $\mathrm{x}$ ambientes, entre os pares de ambientes de mesma época, foi de $81 \%$, (76\% nas águas e $87 \%$ na seca), semelhante à média entre pares de épocas diferentes, que foi de 77\% (Tabela 5). A estimativa de correlação de Spearman, obtida com a média geral dos genótipos em cada época, foi de 0,72. Esses resultados confirmam o que se relatou anteriormente.

Tabela 6. Resumo da análise conjunta de variância para a produtividade de grãos, com decomposição da interação genótipos x ambientes, dos oito ensaios de feijoeiro comum conduzidos nos municípios de Ponta Grossa, PR, e Abelardo Luz, SC, em 2003 e 2004.

\begin{tabular}{lrccr}
\hline Fonte de Variação & GL & Quadrado médio & $\mathrm{P}^{(1)}$ & $\mathrm{R}^{2}$ \\
\hline Genótipos (G) & 15 & 1.449 .290 & 0,000 & 7,6 \\
Locais (L) & 1 & 5.854 .394 & 0,000 & 2,0 \\
Épocas (E) & 1 & 110.493 .251 & 0,000 & 39,5 \\
Anos (A) & 1 & 19.501 .248 & 0,000 & 6,8 \\
GxL & 15 & 950.120 & 0,000 & 5,0 \\
GxE & 15 & 294.677 & 0,035 & 1,5 \\
GxA & 15 & 580.626 & 0,000 & 3,0 \\
LxE & 1 & 8.038 .838 & 0,000 & 2,8 \\
LxA & 1 & 4.391 .282 & 0,000 & 1,5 \\
ExA & 1 & 5.300 .190 & 0,000 & 1,8 \\
GxLxE & 15 & 141.454 & 0,606 & 0,7 \\
GxLxA & 15 & 209.770 & 0,214 & 1,1 \\
GxExA & 15 & 768.719 & 0,000 & 4,0 \\
LxExA & 1 & 22.825 .726 & 0,000 & 8,0 \\
GxLxExA & 15 & 165.337 & 0,446 & 0,9 \\
Resíduo & 256 & 163.790 & - & 14,6 \\
\hline Total & 383 & - & - & - \\
\hline Média (kg ha ${ }^{-1}$ ) & \multicolumn{5}{c}{2.929} \\
CV (\%) & (1)Probabilidade de existência de diferenças significativas entre genótipos.
\end{tabular}

Pelo exposto, existe diferença entre as épocas de semeadura e há interação entre os genótipos e as épocas; contudo, não há alteração significativa na classificação dos genótipos. Dessa forma, pode-se inferir que a avaliação nas duas épocas de semeadura é importante, mas não obrigatória. Assim, para a região de altitude intermediária, nos Estados do Paraná e Santa Catarina, não seria necessária a indicação de cultivares específicas para cada época, e a escolha de um genótipo de adaptação geral às duas épocas é tecnicamente viável. Essa seria a melhor estratégia de recomendação de cultivares para essa região. Além disso, existem outros fatores que favorecem essa recomendação, como o baixo índice de utilização de sementes de feijoeiro-comum pelos agricultores, que é próximo a $13 \%$ (Barros, 2008), e os altos custos que envolvem a avaliação de linhagens em cada época de semeadura separadamente, o lançamento de novas cultivares e a produção de sementes.

\section{Conclusões}

1. A interação genótipos x épocas de semeadura está presente na região de altitude intermediária dos estados do Paraná e Santa Catarina.

2. Nessa região, a parte complexa da interação genótipos $\mathrm{x}$ épocas de semeadura tem pequena importância e, consequentemente, a classificação dos genótipos nas duas épocas é pouco alterada.

3. Não é necessária a indicação de cultivares específicas para cada época de semeadura, na região de altitude intermediária dos estados do Paraná e Santa Catarina.

\section{Referências}

ANNICCHIARICO, P. Cultivar adaptation and recommendation from alfafa trials in Northern Italy. Journal of Genetics and Plant Breeding, v.46, p.269-278, 1992.

BARROS, A.C.S.D.A. A estatística a produção de sementes no Brasil: indicativos do crescimento da agricultura brasileira. SEED News, v.7, p.16-18, 2008.

BRASIL. Instrução Normativa $n^{\circ}$ 25, de 23 de maio de 2006. Estabelece os critérios mínimos a serem observados para a determinação do valor de cultivo e uso - VCU de feijão e os respectivos formulários anexos para inscrição de cultivares no Registro Nacional de Cultivares. Anexo I. Requisitos mínimos para determinação do valor de cultivo e uso de feijão (Phaseolus vulgaris) para a inscrição no Registro Nacional de Cultivares - 
RNC. Diário Oficial [da] República Federativa do Brasil, 19 jun. 2006. Seção 1, p.16.

CARBONELL, S.A.M.; AZEVEDO FILHO, J.A. de; DIAS, L.A. dos S.; GARCIA, A.A.F.; MORAIS, L.K. de. Common bean cultivars and line interactions with environments. Scientia Agricola, v.61, p.169-177, 2004.

CRUZ, C.D. Programa Genes: aplicativo computacional em genética e estatística. Viçosa: UFV, 2007. Disponível em: <http:// www.ufv.br/dbg/genes/genes.htm>. Acesso em: 08 jul. 2010.

CRUZ, C.D.; CASTOLDI, F.L. Decomposição da interação genótipos x ambientes em partes simples e complexa. Revista Ceres, v.38, p.422-430, 1991.

CRUZ, C.D.; REGAZZI, A.J.; CARNEIRO, P.C.S. Modelos biométricos aplicados ao melhoramento genético. 3.ed. Viçosa: UFV, 2004. 480p.

FEIJÃO: dados de conjuntura da produção de feijão (Phaseolus vulgaris L.) e caupi (Vigna unguiculata (1.) walp) no Brasil: 1985 - 2008. Disponível em: <http://www.cnpaf.embrapa.br/apps/ socioeconomia/index.htm>. Acesso em: 8 jul. 2010.

FERREIRA D.F. SISVAR: um programa para análises e ensino de estatística. Revista Symposium, v.6, p.36-41, 2008.

MATOS, J.W. de; RAMALHO, M.A.P.; ABREU, Â. de F.B. Trinta e dois anos do programa de melhoramento genético de feijoeiro comum em Minas Gerais. Ciência e Agrotecnologia, v.31, p.1749-1754. 2007.
MELO, L.C.; MELO, P.G.S.; FARIA, L.C. de; CABRERA DIAZ, J.L.; DELPELOSO, M.J.; RAVA, C.A.; COSTA, J.G.C. da. Interação com ambientes e estabilidade de genótipos de feijoeiro-comum na Região Centro-Sul do Brasil. Pesquisa Agropecuária Brasileira, v.42, p.715-723, 2007.

OLIVEIRA, G.V. de; CARNEIRO, P.C. de S.; DIAS, L.A. dos S.; CARNEIRO, J.E. de S.; CRUZ, C.D. Factor analysis in the environment stratification for the evaluation of common bean cultivars. Crop Breeding and Applied Biotechnology, v.5, p.166-173, 2005.

PEREIRA, H.S.; MELO, L.C.; FARIA, L.C. de; DEL PELOSO, M.J.; COSTA, J.G.C. da; RAVA, C.A.; WENDLAND, A. Adaptabilidade e estabilidade de genótipos de feijoeiro-comum com grãos tipo carioca na Região Central do Brasil. Pesquisa Agropecuária Brasileira, v.44, p.29-37, 2009.

RAMALHO, M.A.P.; ABREU, A.F.B.; SANTOS, P.S.J. Interações genótipos $\mathrm{x}$ épocas de semeadura, anos e locais na avaliação de cultivares de feijão nas Regiões sul e Alto Paranaíba em Minas Gerais. Ciência e Agrotecnologia, v.22, p.176-181, 1998.

SCOTT, A.J.; KNOTT, M. A Cluster analysis method for grouping means in the analysis of variance. Biometrics, v.30, p.507-512, 1974.

ZIMMERMANN, F.J.P. Estatística aplicada à pesquisa agrícola. Santo Antônio de Goiás: Embrapa Arroz e Feijão, 2004. 402p.

Recebido em 15 de julho de 2009 e aprovado em 14 de maio de 2010 